\title{
Assessing Public Awareness and Knowledge of Stroke: A Case of Kumasi, Ghana
}

\author{
Yinghua Chen \\ Department of Public Administration, School of Management, Jiangsu University, Zhenjiang \\ 212013 China, Email: touchstones8@ hotmail.com \\ Adu Amankwaa Isaac (Corresponding Author) \\ Department of Public Administration, School of Management, Jiangsu University, Zhenjiang \\ 212013 China, Email: amassju65@gmail.com \\ Mandella Osei-Assibey Bonsu \\ Faculty of Corporate Finance, School of Finance and Economics, Jiangsu University, China, \\ Email: thugdibae1@gmail.com \\ Gasper Neema Mariwa \\ School of Management, Jiangsu University, Zhenjiang 212013 China \\ Email: Annybird28@gmail.com
}

Received: July 10, 2019 Accepted: August 4, 2019

doi:10.5296/jbls.v10i2.15263 URL: https://doi.org/10.5296/jbls.v10i2.15236

\begin{abstract}
Background: The public awareness of stroke risk factors and warning signs is very imperative the in the quest to prevent diseases. In Ghana, public awareness of stroke as well as awareness of the effect of stroke is presently borne. The study attempts to examine the public awareness of stroke in Ghana. It also seeks to assess the risk factors associated with stroke.
\end{abstract}

Methods: The study was a cross-sectional with 220 households in the Kumasi suburb. The study used structured questionnaires to ascertain data and logistics regression analyses to classify predicators on the recognition of stroke awareness, risk factors and stroke warning signs.

Findings: It was revealed that, headache and numbness were the major stroke warning signs acknowledged and cited by respondent, and the commonest variable (factor) associated with stroke risk factors is ailing to exercise (44\%). The findings of the logistic regression model on the predictors of stroke awareness showed that, stroke risk factors $(\mathrm{OR}=2.27, \mathrm{CI}=\mathrm{CI}=$ 
1.52-3.71, $\mathrm{p}<0.001)$ and religion $(\mathrm{OR}=11.66 \mathrm{CI}=1.37-161.01), \mathrm{P}<0.02)$ were linked with greater level of stroke risk factors.

Conclusions: Though, stroke is seen as the common causes of mortality in Ghana, but our study showed appreciable number of respondents awareness of it risk factors, warnings signs and the fact that it is a topmost killer. This satisfactory was attributed to the sources of information and other imperative factors such as mounting stroke campaign programmes. Therefore, stroke campaign programmes and health education programmes should be rigorously mounted in universities, high schools, colleges so as to create the needed awareness of this killer disease, it risk factors and warning signs.

Keywords: stroke, warning signs, risk factors, Kumasi, Ghana

\section{Introduction}

Stroke has been recognized as the second leading cause of death with an annual mortality rate of 5.5million. The American Heart Association documented that, close to 795,000 people experience new or recurrent stroke each year. Stroke is a disease of colossal public health imperative with economic and social effects. The burden of stroke does not only rest in the high mortality, but the high morbidity also leads up to 60 percent of lives being systematically being disabled. However early detection and treatment are crucial in reducing the risk of disability and death when stroke occurs.

Stroke was a disease of the developed countries, until recently. In fact, via the application of empirical evidence-based fighting measures, the burden of stroke has been reduced to its barest minimum in many developed economies. In 1975 as cited in Lopez et al (2011), the death of stroke has reduced by $20-50 \%$ in a pronounced countries such as Italy, Austria, Iceland, and Germany respectively (Pontes-Neto et al, 2008). However, developing countries are now experiencing the burden of stroke and recently two-thirds of stroke mortality cases happen in sub-Saharan Africa, where contagious diseases such as HIV/AIDS, poverty, and malnutrition also apply their terrific toll (Murray CJL, Lopez AD 1997).

Stroke is recognized as the most combating neurological disease, and this is mainly of its risk hazards such as high cholesterol, hypertension, diabetes, and smoking can be prevented either via well lifestyle alternatives or medications. To get along of stroke, speedy access to medical treatment is very significant, as delays lead to poor results. According to Ntaios, G., et al. (2015), lack of knowledge of stroke signs and symptoms is a crucial causal risk of delay in health centers disclosing of stroke.

In Australia, 82\% of stroke patients present to the hospital as an emergency (Bosu WK, 2007). However, only $41 \%$ arrive at the hospital within 4.5 hours of stroke onset (Donkor et al, 2014). In the United Kingdom (UK), only $48 \%$ of stroke patients send to the hospital as an emergency, and $37 \%$ present within 3 hours of symptom onset. The increased public awareness of stroke hazard or risk factors and warning signs and symptoms is significant in the combat of stroke, and health rigorous programmes have been useful in this regard. Currently, the pressure of stroke is borne in Sub-Saharan Africa of which Ghana is of no exception. 
In the Ghanaian community, stroke is ranked as the three most critical causes of immortality. De-Graft Aikins A, (2007) as cited by Donkor et al, (2014), the burden of it is increasing. Studies have shown that hypertension is high with a percentage of (19-48\%) which is one of the high prevalence of stroke risk factors. This evidently shows that this part describes the drift of rising of stroke in the Ghanaian community. The dominance of stroke has been linked to the poor awareness and knowledge by the Ghanaian populace. The evidence of the awareness and knowledge of stroke warning signs and risk factors is rare. To aid create the awareness and knowledge of stroke warning signs and risk factors, this study conducts a cross sectional approach of households in the Kumasi Suburb, Ghana to gather insights regarding on the public awareness and knowledge of stroke risk factors and warning signs.

Our research contributes to the existing literature on the knowledge and awareness of stroke in a number of ways. To begin, we used cross sectional approach to evaluating the public awareness and knowledge of stroke using household from the Kumasi Suburb, Ghana. Most literatures focused in the western nations when examining the knowledge and awareness of stroke, far too attention has been paid to this significant issue in developing countries like Ghana. However, the death of Ghanaian populace as result of stroke is increasing significantly in the coming years, but stakeholders and government up to now has taken no specific action to educate the populace on the risk factors and warning signs of stroke. Thus, it is imperative to comprehend the tendency of public awareness of stroke in the country and corresponding factors. We believed the results of this study will be paramount in helping Practioners, government, and the Ghanaian populace on the evidence of the significant knowledge and awareness of stroke warning signs and risk factors. It will aid us to employ more effective, understandable, educational programs to increase the public awareness and knowledge of stroke and thus bring the burden of stroke to the barest minimum. To the best of our knowledge, this research is the first cross sectional survey that examine the level of awareness and knowledge of stroke among Ghanaian populace especially in the Kumasi Suburb.

The rest of the manuscript assumes the following structures. The next section reviews the literature. Section 3 is the research subject and Method, section 4 addresses the findings, results and discussions and section 5 concludes and provides several policies implications

\section{Related Literature Review}

Stroke is a major challenge fronting healthcare being one of the leading causes of death and one of the major causes of disability and dependency in the activity of daily living worldwide (Bay CL, 2001). Stroke is defined as the rapid spread clinical signs of focal disturbance of cerebral function lasting more than 24 hours or resulting to death, with no obvious causes other than the vascular origin World Health Organization (WHO). The definition of stroke by WHO is still globally used, the world Health Organizations definitions depend heavily on clinical signs and is now reviewed outmoded by the American Heart Association and America Stroke Association as results to important advances in the nature, timing, clinical acknowledge of stroke and its parody, and imaging results that require an updated definition. (Ntaios et al., 2015). 
Notwithstanding advancement in the diagnosis and treatment of cardiovascular disease or accident through medical advances, it is still the largest single cause of disability and the second leading cause of death on a global scale (Donkor et al: 2014). Not only that, despite improvements in the treatment of cardiovascular disease through medical advances and Government targets, adherence to secondary prevention measures is reportedly low with one study of over 2000 ischemic stroke patients reporting one quarter discontinuing one or more of their prescribed secondary prevention medications within 3 months (Bushnell C. et al, 2009).

Most prior studies also reveal that early recognition and urgent transfer to stroke centers to ensure patients receive medical treatment within hours of stroke onset significantly improve survival rates (Travis LH, et al 2003). In view of that risk management has been diploid to develop significant strategies to prevent both primary and secondary stroke. However, according to (Julia S, 2013) patient awareness of stroke risk is significantly low and adherence to secondary prevention measures is inadequately poor. In a studies conducted by Thaworn Lorga, Janthila Srikrajang and Suchart et al, on the awareness and knowledge of stroke and hypertension among area residents in Kentucky with a population of 1.3 million. A sampling scheme was used to ascertain cases in the out-of-hospital setting. Despite the fact that in coronary artery disease or in coronary supply route ailment convictions have been shown to impact behavior with perception of progressively genuine outcomes foreseeing better adherence, this has not been the situation for stroke survivors. The purposes behind this are vague in any case, the distinctions may have something to do with the patient's view of their danger of further illness.

Universal examinations have demonstrated that patients are far-fetched to call for urgent intervention in the event that they or a family member suffers a stroke. This proposes for primary stroke, they and or their relatives either don't see the direness in the need for attention for stroke or accept regardless of whether they rush to the hospital nothing can be done. According to (Pancioli AM, Broderick J, Kothari R, et al., 1998), the risk factors and warnings associated with stroke are found to be ascetically poor, even among those who are aware of having risk factor stroke (Yoon SS, Heller RF, Levi C, et al., 2001).

Wahab KW admitted that, late reporting to the hospital could be as results of poor awareness of the warnings of stroke by the general population. Admittedly, among the Ghanaian community, cardiovascular disease or stroke is the second common cause of death and the leading cause of long-term disability, hence places terrific demands on family members and caregivers.

\section{Subject and Methods}

The research was conducted in Ghana, Kumasi, and the second largest city of Ghana. Ghana is a country which shares boarders with Togo and Ivory Coast in West Africa. Ghana is lower middle income status nation with literacy rate $76.6 \%$ and life expectancy rate of approximately 63 percent.(Kamalian \& Lev, 2019). Kumasi is the capital of Ashanti region, in southern Ghana. It's known as Garden city as a center for Ashanti culture and beatification. 
According to the United Nations (2010), Kumasi is highly urbanized and diverse with population of 1.7 million. Kumasi has five health district and having about 26 hospital with Komfo Anokye Teaching hospital as the main hospital which serves the city and as well as it immediate peri-urban community. There is also a spread of herbal centers in Kumasi, which offer non-orthodox medical services for a varied range of diseases including stroke.

\subsection{Sampling and Settings}

The study employed cross sectional approach. The population of the study was made up of household from one person between 18 and 65 years of age that was randomly selected for interview using a structured questionnaires. The reason of choosing this age range is to increase the likelihood of finding accurate responses from the study participants.

\subsection{Measures}

A literature review of preceding studies regarding stoke knowledge and hospital awareness was done to classify likely items for the structured questionnaires. Based on the review, the structured questionnaires were established that addressed the knowledge of stroke, risk factors, and warning signs symptom in a distinct geographical settings. The questionnaires on the study were verified for its validity before administered. With this, specialists from the Ghana Health Service and medical Practioners of about twenty-five evaluated the questionnaires for quality reassurance of the measurement of the study aims, hence irrelevant items were lashed out before it was sent out to the targeted participant.

The study questionnaires contained twenty-eight question that divided into 4 sections. The first part of the study questionnaires dealt on the knowledge about stroke (5 items). These items talked knowledge concerning risk factors, warning signs, and treatment of stroke; information resources; and recognition of any public stroke association. Response options for each of these items were open-ended questions. The second part of the questionnaires addressed the planned response to acute stroke (open-ended question) and planned response to 6 stroke warning signs (close-ended questions) that is dizziness; tingling/numb or dead sensation; weakness or paralysis on 1 side of body; blurred or double vision; difficulty speaking, reading, and unadorned headache), the third section was on respondents' demographic details (age, sex, marital status, country of origin, education, income), and the final sections asked on respondents' presence of stroke risk factors (high blood pressure, angina, heart attack, previous stroke, diabetes, high cholesterol, smoking, alcohol, and family history of stroke). This study was approved by Ghana Health Service and Ministry of Health and the respondent was notified with their consent.

\subsection{Data Analysis}

The study data collected were mostly quantitative, and qualitative and were analyzed using" SPSS, Microsoft Excel package, and Web Chi Square calculator. Descriptive statistics such as frequencies, percentages, would be used to report and present data out of the study variables. However, logistics regression analyses were done to identify predicators of the main outcome variables together with risk factors, and stroke warning signs affected by stroke. The independent variables in the regression analyses are gender, age, religion, income, educational 
level, and the presence of at least one stroke risk factors. With this, for each regression model, response options for the dependent variable were categorized as either "know" or "do not know." Two-tailed significance tests were used, and $\mathrm{P}$ is less than 0.5 was considered significant in both multivariate analyses. Missing data were excluded in the regression analysis. The significance of predictor variables were evaluated by $\mathrm{p}$ values, odds ratios and confidence intervals from Wald statistics; $\mathrm{p}$ values $\leq 0.05$ were measured as significant.

\section{Data Presentation, Results, and Findings}

This sections displays the data, results and findings of the study.

Table 1 Respondent of profile and stroke risk factor profiles of the Respondent

\begin{tabular}{|c|c|c|c|}
\hline Description & & Percentages & Frequency \\
\hline \multirow[t]{2}{*}{ Gender } & Male & 73 & 160 \\
\hline & Female & 27 & 60 \\
\hline \multirow[t]{5}{*}{ Age Group } & $<30$ years & 24.5 & 54 \\
\hline & 40-49years & 24.09 & 53 \\
\hline & $50-59$ years & 24.09 & 53 \\
\hline & $60-65$ years & 18.1 & 40 \\
\hline & $>65$ years & 9.09 & 20 \\
\hline \multirow[t]{4}{*}{ Edu. Level } & High School & 31.8 & 70 \\
\hline & Diploma & 31.3 & 69 \\
\hline & First Degree & 20.4 & 45 \\
\hline & No formal Edu. & 16.3 & 36 \\
\hline \multirow[t]{5}{*}{ Income Level } & $500 \$$ & 9.09 & 20 \\
\hline & $700 \$$ & 8.18 & 30 \\
\hline & $900 \$$ & 40.9 & 90 \\
\hline & $1000 \$$ & 9.09 & 20 \\
\hline & Unemployed & 27.27 & 60 \\
\hline \multirow[t]{4}{*}{ Religion } & Christianity & 22.72 & 50 \\
\hline & Muslim & 20 & 44 \\
\hline & Traditional Believe & 30 & 66 \\
\hline & Atheist & 27.27 & 60 \\
\hline \multirow[t]{3}{*}{$\begin{array}{c}\text { Marital } \\
\text { Status }\end{array}$} & Married & 45 & 100 \\
\hline & Single & 41 & 90 \\
\hline & Divorced & 14 & 30 \\
\hline \multirow[t]{6}{*}{$\begin{array}{c}\text { Stroke Risk } \\
\text { Factors } \\
\end{array}$} & High Blood pressure & 11 & 25 \\
\hline & Diabetes & 13 & 28 \\
\hline & Smoking & 23 & 51 \\
\hline & Hypertension & 14 & 32 \\
\hline & Cholesterols & 20 & 43 \\
\hline & Back pain & 19 & 41 \\
\hline
\end{tabular}

A total of 220 inhabitants of Kumasi suburb were sampled in this study and their respondent profiles as well as their risk factors associated with stroke. From the table illustrated above (table 1$)$, one hundred and sixty $(n=160)$ of the respondent were males representing $73 \%$, while $n=80$ representing $27 \%$ were females.

Ages below 30 years $(n=54,24.5 \%)$ were the commonest and highest age attained by the respondents. It is followed by ages between 40-59 years with a frequency number of $(n=53)$ signifying a percentage of $24.09 \%$. 


\section{I Macrothink}

Journal of Biology and Life Science ISSN 2157-6076 2019, Vol. 10, No. 2

However, High school education was the commonest education level achieved by the respondent $(n=70)$ with a percentage of $31.8 \%$ and it is followed by diploma $(n=69,31.3 \%)$. Respondent with illiteracy rate was relatively low $(n=36)$ representing $16.3 \%$. It is interesting to note that, majority of the respondent were jobless meaning unemployed ( $\mathrm{n}=70,32 \%)$, and the most common earning range for the respondents were $900 \$$ corresponding to $40.9 \%$, $\mathrm{n}=90$. Marital status of the respondents presented comparable extents for those married. Additionally, twenty-three percent $(23 \%)$ of the respondent was common to smoking as risk stroke factor, $(n=51)$, followed by Cholesterols $(n=43,20 \%)$. The least stroke risk factor associated with the respondents were high blood pressure $(n=25,11 \%)$.

Table 2. Knowledge of stroke risk factors and Signs

\begin{tabular}{l|c|c}
\hline \multicolumn{1}{c}{ Factors } & \multicolumn{2}{c}{ Number } \\
\hline \multicolumn{1}{l|}{ Risk Factors } & 90 & 41 \\
\hline Lack of exercise & 78 & 35.45 \\
\hline Alcohol & 78 & 35.45 \\
\hline High Cholesterol & 89 & 40.45 \\
\hline Stress & 53 & 24 \\
\hline Diabetes & 61 & 28 \\
\hline Hypertension & 130 & $59(1)$ \\
\hline Warning signs & 90 & $41(5)$ \\
\hline Severe headache & 79 & $36(6)$ \\
\hline Slurred speech & 110 & $50(2)$ \\
\hline Weakness & 77 & $35(7)$ \\
\hline *Numbness & 91 & $41(5)$ \\
\hline Dizziness & 100 & $45(3)$ \\
\hline No knowledge of warning signs & 97 & $44(4)$ \\
\hline Unspecified pain & \multicolumn{2}{|c}{} \\
\hline Vision problems & 83 & $38(1)$ \\
\hline Household history of stroke & 45 & $20(2)$ \\
\hline Smoking & \multicolumn{2}{|l}{} \\
\hline Heart disease &
\end{tabular}

Respondents were examined on their knowledge concerning the stroke risk factors. The respondent's recognition of stroke factors and warnings signs are illustrated in the table above (Table 2). According to the respondents, the commonest variable (factor) associated with risk factors of stroke is ailing to exercise. It has the highest percentage of $41 \%$. It is followed by stress $(40.45 \%)$. The least risk factor is diabetes. On the side of stroke warnings, the respondent cited severe headache as the familiar warning signs with a percentage rate of 59\%, $\mathrm{n}=130)$, it is followed by numbness $(\mathrm{N}=110,50 \%)$, unspecified pain ranked third $(\mathrm{N}=90$, $41 \%)$. The least warning signs according to the respondent is dizziness $(35 \%)$.

It is worthy to note that, respondent's knowledge concerning the established warning signs was better than the knowledge for risk factors. One hundred and seventy (170) representing (77\%) correctly listed established warnings signs, one hundred and forty (140) representing $63 \%$ correctly listed 3 risk factors correctly, and 80 (24.1\%) correctly listed \$3 established risk factors for stroke. 
Table 3. Stroke awareness through logistic regression

\begin{tabular}{|c|c|c|c|c|}
\hline \multirow[t]{2}{*}{ Variable } & \multicolumn{2}{|r|}{ Risk factors } & \multicolumn{2}{|r|}{ Warning signs } \\
\hline & $\mathbf{p}$ & OR (95\% CI) & $\mathbf{p}$ & OR $(95 \%$ CI $)$ \\
\hline Age $<65$ years & 0.67 & $(0.57-1.61)$ & 0.92 & $(0.59-1.80)$ \\
\hline Gender & 0.11 & $(0.87-1.88)$ & 0.95 & $(0.65-1.49)$ \\
\hline Religion & 0.02 & $11.66(1.37-161.01)$ & 1.00 & $0.00(0.00-23.09)$ \\
\hline Education Level & 0.23 & $(0.71-3.52)$ & 0.25 & $(0.70-3.92)$ \\
\hline risk factor & $<0.01$ & $(1.52-3.71)$ & 0.06 & $(0.98-2.52)$ \\
\hline
\end{tabular}

Table 4. Awareness of Stroke Risk Factors and Warning signs

\begin{tabular}{c|c|c}
\hline Variables & Number & Percentage \\
\hline \multicolumn{3}{|c|}{ Factors } \\
\hline Ses & 161 & $73.2 \%$ \\
\hline No & 59 & $26.8 \%$ \\
\hline Yes & 120 & $54.5 \%$ \\
\hline No & 100 & $45.5 \%$ \\
\hline \multicolumn{3}{|c}{ Previous information about stroke } \\
\hline Mass Media & 90 & $40.9 \%$ \\
\hline Reading book & 30 & $13.6 \%$ \\
\hline Friends and Family & 50 & $22.7 \%$ \\
\hline News papers & 20 & $9.2 \%$ \\
\hline Other means & 30 & $13.6 \%$ \\
\hline \multicolumn{3}{c}{} \\
\hline Mass media audiovisual & Recommended sources of information \\
\hline Others & 130 & $59 \%$ \\
\hline Educational booklets & 70 & $31.8 \%$ \\
\hline
\end{tabular}

From (table 3 ) shows the findings of the logistic regression model on the predictors of stroke awareness. From the table, having stroke risk factors $(\mathrm{OR}=2.27, \mathrm{CI}=\mathrm{CI}=1.52-3.71, \mathrm{p}<$ $0.001)$ and religion $(\mathrm{OR}=11.66 \mathrm{CI}=1.37-161.01), \mathrm{P}<0.02)$ were linked with greater level of stroke risk factors.

Meanwhile no significant relationship were perceived assisted between awareness of stroke warning signs and any of the explanatory variables examined. Respondent were asked on the organ associated with stroke. According to the respondent $40 \%(\mathrm{n}=277)$ of the respondents correctly mentioned the brain, $10 \%(n=69)$ mentioned the heart, $44 \%(n=305)$ mentioned other parts of the body which are not organs at all, and 6\% $(\mathrm{n}=42)$ indicated they did not know the answer. In the multiple logistic regression analysis (Table 3), identification of brain as the organ affected by stroke was significantly associated with younger age, that is age $<50$ years $(\mathrm{OR}=0.56, \mathrm{CI}=0.35-0.92, \mathrm{p}=0.021)$.

\section{Discussion and Conclusions}

The study examined the public awareness of stroke risk factors and warning signs in Kumasi, Ghana. The findings from the study shows that, stroke as a disease is very preventable and lifestyles efforts could be made to bring this to the barest minimum. The findings depicts that 
there is still poor community awareness of stroke risk factors and warning signs. Majority of the respondent could not acknowledged diabetes and hypertension which is known to be the most imperative risk factor in sub-Sahara Africa country specifically Ghana.

Respondent were able to recognize and mentioned stress and lack of exercise as the commonest risk factor associated with stroke. Stress is commonly perceived that, when people works wholeheartedly without rest are at risk of attaining stroke. Further, people who do not exercise are also at risk of stroke. This findings are consistent with Donkor et al, (2014), in which the respondent perceived and cited lack of exercise as the major commonest and known risk factor associated with stroke. A study conducted by Hosseininezhad et al (2017) shows that, hypertension was the major stroke risk factor. It seems that, the awareness regarding stroke risk factors in Ghana was seen to be low. Ghana is a stroke troubled country (Donkor et al, 2014), thus poor knowledge of risk factors is of serious concern. Numerous stroke risk factors has also been informed in Africa. In Nigeria as cited in Donkor et al, (2014), majority of the respondent correctly recognizing major risk factors associated with stroke. The study was conducted among university staffs and students in Nigeria.

Headache and numbness were the major stroke warning signs acknowledged and cited by respondent. In this study, majority of the participant were having no knowledge of stroke warning signs and could not acknowledge the rudiment stroke warning signs such as vision problems, severe headache and weakness. In a study conducted by J nuerol et al (2017), in Cameroon, respondent identified numbness as the main warning signs. Therefore, most of the educational efforts, mass media, and hospitals in the future should be concentrated on increasing the knowledge and more importantly the awareness of stroke warning signs in the Ghanaian community especially in Kumasi Suburb.

We examined the public awareness of stroke risk factors and the warning signs in our study. In our study, the percentage rate on the awareness of stroke risk factors and warnings signs was greater than $65 \%$. The percentage score or the respondent correctly aware of the risk and warning signs are more than $60 \%$ of all cases. As cited by Hosseininezhad et al (2017), Pancioli et al, conducted a survey on telephone, it was revealed that, $57 \%$ of subjects are aware of at least one warning signs and $68 \%$ of the respondents mentioned at least one stroke risk factor. In Saudi Arabia, Alaqeel, et al.23 discovered that $21.7 \%$ of the respondents correctly selected $\geq 5$ risk factors and ended $\leq 1$ mistake and $18.4 \%$ of the respondents correctly identified $\geq 3$ symptoms of the list and make $\leq 1$ mistake.

The study reveals that, people's awareness of stroke risk factors and warning signs was based on family and friends which most of the respondents reported yes. However, the major sources of information by the respondent about stroke risk factors and it warning signs were mass media, and then family and friends. The least sources of information according to the respondent on the stroke warning signs and risk factors was newspaper reading. In a study by Kim, et al, (2012), mass media was revealed as the major sources of information about stroke risk factors and it warning signs. It had a percentage of (59\%) with the internet rated as the second greatest sources of information with a percentage rate of $(37 \%)$. In the same way, Alaqeel, et al. (1999) on their studies reported (49.9\%) of the participants cited and 
mentioned mass media as the sources of knowledge and information of stroke. Mass media audiovisual is tipped as the most and major source of information by respondent. With this, mass media can be effective in drawing the awareness of warning signs and risk factors of stroke to the Ghanaian populace, broaden to the West Africa countries as well as other developed countries on the globe. The findings from the study shows that public awareness of stroke risk factors and warning signs are still poor in Kumasi and Ghana in general. Even though, stroke is known as one of the three most common causes of mortality in Ghana currently, but the study depicts that, appreciable number of respondents are aware of it risk factors, warnings signs and the fact that it is a topmost killer. Therefore, the study would conclude that, awareness of the public about stroke, its risk factors and warning signs was satisfactory. This satisfactory result can be attributed to the sources of information and other imperative factors such as stroke awareness campaign programmes.

\subsection{Policy Recommendations}

In Ghana, stroke is ranked as the three most critical causes of immortality and the burden of it is increasing. This is probably the fact that, more attention has been given to other diseases such as malaria, HIV Aids etc. The study would recommend that, stroke campaign programmes and health education programmes should be rigorously mounted in Kumasi especially in universities, high schools, colleges so as to create the needed awareness of this killer disease, it risks factors and warning signs. This will go a long way to decreasing the risk of stroke and improving the rapidity of hospital staging after inception of stroke. The research concentered on the Kumasi suburb, so, findings arrived at should not be subjected to the whole Ghanaian community, and developing countries. Therefore, this caveat calls for further studies, which could extent to the rural communities in Ghana to examine their awareness and knowledge of stroke.

\section{Acknowledgments}

The authors would like to acknowledge the precious remarks of the unknown referees.

\section{Conflicts of Interest}

The authors declare no conflicts of interest.

\section{References}

Alaqeel, A., AlAmmari, A., AlSyefi, N., Al-Hussain, F., \& Mohammad, Y. (2014). Stroke awareness in the Saudi community living in Riyadh: prompt public health measures must be implemented. J Stroke Cerebrovasc Dis., 23(3), 500-504.

https://doi.org/10.1016/j.jstrokecerebrovasdis.2013.04.011

Bay, C. L. (2001). Quality of life of stroke survivors: a research synthesis. J Neurosci Nurs., 33, 3106. https://doi.org/10.1097/01376517-200112000-00005

Bosu, W. K. (2007).Ghana's National NCD Programme: history, prospects, and challenges. Accra: Paper presented at the 1st Annual Workshop, UK-Africa Academic Partnership on Chronic Disease, Noguchi Memorial Institute for Medical Research. 
Bushnell, C., Zimmer, L., Schwamm, L., Goldstein, L. B., Clapp-Channing, N., Harding, T., ... \& Peterson, E. (2009). The Adherence eValuation After Ischemic Stroke Longitudinal (AVAIL) registry: design, rationale, and baseline patient characteristics. American heart journal, 157(3), 428-435. https://doi.org/10.1016/j.ahj.2008.11.002

De-Graft, A. A. (2007). Ghana's neglected chronic disease epidemic: a developmental challenge. Ghana Med J., 41, 154-159.

Donkor, E. S., Owolabi, M. O., Bampoh, P., Aspelund, T., \& Gudnason, V. (2014). Community awareness of stroke in Accra, Ghana. BMC Public Health, 14(1), 196. https://doi.org/10.1186/1471-2458-14-196

Hosseininezhad, M., Ebrahimi, H., Seyedsaadat, S. M., Bakhshayesh, B., Asadi, M., \& Ghayeghran, A. R. (2017). Awareness toward stroke in a population-based sample of Iranian adults. Iran J Neurol., 16(1), 7-14.

Hosseininezhad, M., Ebrahimi, H., Seyedsaadat, S. M., Bakhshayesh, B., Asadi, M., \& Ghayeghran, A. R. (2017). Awareness toward stroke in a population-based sample of Iranian adults. Iranian journal of neurology, 16(1), 7-14.

Kamalian, S., \& Lev, M. H. (2019). Stroke Imaging. Radiologic Clinics of North America, 57(4), 717-732. https://doi.org/10.1016/j.rcl.2019.02.001

Kim, J. S., \& Yoon, S. S. (1997). Perspectives of stroke in persons living in Seoul, South Korea. A survey of 1000 subjects. Stroke, 28(6), 1165-1169. https://doi.org/10.1161/01.STR.28.6.1165

Kim, Y. S., Park, S. S., Bae, H. J., Heo, J. H., Kwon, S. U., Lee, B. C., ... \& Yoon, B. W. (2012). Public awareness of stroke in Korea: a population-based national survey. Stroke, 43(4), 1146-1149. https://doi.org/10.1161/STROKEAHA.111.638460

Lopez, A. D., Mathers, C. D., Ezzati, M., Jamison, D. T., \& Murray, C. J. (2006). Global and regional burden of disease and risk factors, 2001: systematic analysis of population health data. Lancet, 367(9524), 1747-1757. https://doi.org/10.1016/S0140-6736(06)68770-9

Murray, C. J. L., \& Lopez, A. D. (1997). Mortality by cause for eight regions of the world: global burden of disease study. Lancet, 349, 1269-1276.

https://doi.org/10.1016/S0140-6736(96)07493-4

Ntaios, G., Melikoki, V., Perifanos, G., Perlepe, K., Gioulekas, F., Karagiannaki, A., ... \& Poulikakou, M. (2015). Poor stroke risk perception despite moderate public stroke awareness: insight from a cross-sectional national survey in Greece. Journal of Stroke and Cerebrovascular Diseases, 24(4), 721-724.

https://doi.org/10.1016/j.jstrokecerebrovasdis.2014.07.055

Pancioli, A. M., Broderick, J., Kothari, R., Brott, T., Tuchfarber, A., Miller, R., ... \& Jauch, E. (1998). Public perception of stroke warning signs and knowledge of potential risk factors. Jama, 279(16), 1288-1292. https://doi.org/10.1001/jama.279.16.1288 


\section{Macrothink}

Journal of Biology and Life Science ISSN 2157-6076 2019, Vol. 10, No. 2

Pandian, J. D., Jaison, A., Deepak, S. S., Kalra, G., Shamsher, S., Lincoln, D. J., \& Abraham, G. (2005). Public awareness of warning symptoms, risk factors, and treatment of stroke in northwest India. Stroke, 36(3), 644-648.

Pontes-Neto, O. M., Silva, G. S., Feitosa, M. R., De Figueiredo, N. L., Fiorot Jr, J. A., Rocha, T. N., ... \& Leite, J. P. (2008). Stroke awareness in Brazil: alarming results in a community-based study. Stroke, 39(2), 292-296.

https://doi.org/10.1161/STROKEAHA.107.493908

Sacco, R. L., Benjamin, E. J., Broderick, J. P., Dyken, M., Easton, J. D., Feinberg, W. M., ... \& Wolf, P. A. (1997). American heart association prevention conference, IV: prevention and rehabilitation of stroke: risk factors. Stroke, 28, 1507-1517.

https://doi.org/10.1161/01.STR.28.7.1507

Slark, J., \& Sharma, P. (2014). Risk awareness in secondary stroke prevention: a review of the literature. JRSM Cardiovascular Disease, 3. https://doi.org/10.1177/2048004013514737

Travis, L. H., Flemming, K. D., Brown, R. D. Jr., Meissner, I., McClelland, R. L., \& Weigand, S. D. (2003). Awareness of stroke risk factors, symptoms, and treatment is poor in people at highest risk. J Stroke Cerebrovasc Dis., 12(5), 221-227.

https://doi.org/10.1016/j.jstrokecerebrovasdis.2003.09.002

Wardlaw, J., Sandercock, P., \& Berge, E. (2003). Thrombolytic therapy with recombinant tissue plasminogen activator for acute ischemic stroke: where do we go from here? A cumulative meta-analysis. Stroke, 34, 1437-1442.

https://doi.org/10.1161/01.STR.0000072513.72262.7E

World Health Organisation (WHO). Cardiovascular Diseases Fact Sheet No 317. Geneva,http://www.who.int/mediacentre/factsheets/fs317/en/index.html (2011, accessed 15 September 2011)

Yoon, S. S., \& Byles, J. (2002). Perceptions of stroke in the general public and patients with stroke: a qualitative study. BMJ, 324, 1-6. https://doi.org/10.1136/bmj.324.7345.1065

\section{Copyright Disclaimer}

Copyright for this article is retained by the author(s), with first publication rights granted to the journal.

This is an open-access article distributed under the terms and conditions of the Creative Commons Attribution license (http://creativecommons.org/licenses/by/3.0/). 